\title{
Isolation of AmphiCASP-3/7, an ancestral caspase from amphioxus (Branchiostoma floridae). Evolutionary considerations for vertebrate caspases
}

\author{
JR Bayascas ${ }^{1}$, VJ Yuste ${ }^{1}$, E Benito ${ }^{2}, \mathrm{~J}$ Garcia-Fernàndez ${ }^{2}$ \\ and JX Comella*,1 \\ ${ }^{1}$ Grup de Neurobiologia Molecular, Departament de Ciències Mèdiques \\ Bàsiques, Universitat de Lleida, Av. Rovira Roure 44, E-25198 Lleida, Spain \\ 2 Departament de Genètica, Facultat de Biologia, Universitat de Barcelona, \\ Diagonal 645, 08028 Barcelona, Spain \\ * Corresponding author: JX Comella, Av. Rovira Roure 44, E-25198 Lleida, \\ Spain. Tel: +34 973702414; Fax: +34 973702438; \\ E-mail: joan.comella@cmb.udl.es
}

Received 9.10.01; revised 12.3.02; accepted 22.4.02

Edited by SJ Martin

\begin{abstract}
Caspases are a large family of cysteine proteases that play an essential role as effectors of apoptosis in metazoans. Thirteen different caspases have been identified in vertebrates so far, and their function in apoptotic or inflammatory responses is well documented. We have taken advantage of the broadly accepted condition of amphioxus (Cephalochordata, Branchiostoma floridae) as the closest living relative to vertebrates to study the molecular evolution of caspases. Here we report for the first time the pattern of programmed cell death during development of cephalochordates. We also describe the isolation and functional characterisation of the first caspase related gene in amphioxus, which we named AmphiCASP-3/7. The amphioxus caspase is expressed throughout development, from the gastrula to larva stage. AmphiCASP-3/7 induced cell death when ectopically expressed in human HEK 293T cells, and the recombinant protein was inhibited by DEVD peptides. AmphiCASP-3/7 reflects the primitive condition of the executor vertebrates caspases -3 and -7 , prior to vertebrate specific duplication. Interestingly, AmphiCASP-3/7 is functionally closer to vertebrate caspase-7, as shown by substrate specificity both in vitro and in MCF7 cells. Our phylogenetic and functional data help in drawing the evolutionary history of caspases, and illustrates an example of acquisition in vertebrates of novel functional properties after gene duplication.
\end{abstract}

Cell Death and Differentiation (2002) 9, 1078-1089. doi:10.1038/sj.cdd.4401075

Keywords: apoptosis; whole-mount TUNEL; caspases; amphioxus; gene duplication

Abbreviations: Ac-DEVD-afc, acetyl-Asp[OMe]-Glu[OMe]-ValAsp[OMe]-7-amino-4-trifluoromethylcoumarin; Ac-IETD-afc, acetyl-Ile-Glu[OMe]-Thr-Asp[OMe]-7-amino-4-trifluoromethylcoumar- in; Ac-VEID-afc, acetyl-Val-Glu[OMe]-lle-Asp[OMe]-7-amino-4trifluoromethylcoumarin; BCIP, 5-bromo-4-chloro-3-indolyl phosphate; bp, base pair; BSA, bovine serum albumin; CARD, caspase recruitment domain; CHAPS, 3-(3-cholamidopropyl)dimethylammonio)-1-propanesulfonic acid; DED, death effector domain; DTT, dithiotheitol; EDTA, sodium ethylenediaminetetraacetic acid; kb, kilobase; HEK 293T, human embryonic kidney 293T cells; IPTG, isopropyl-1-thio- $\beta$-D-galactopyranoside; NBT, nitro blue tetrazolium; ORF, open reading frame; PBS, phosphate buffered saline; $P C D$, programmed cell death; $P C R$, polymerase chain reaction; PEG, polyethylene glycol; SDS, sodium dodecyl sulphate; TdT, terminal desoxynucleotidiyl transferase; TUNEL, TdT mediated dUTP nick end-labelling; UTR, untranslated region; z-DEVD-fmk, benzyloxycarbonyl-Asp[OMe]-Glu[OMe]-Val-Asp[OMe]-fluoromethylketone; z-VAD-fmk, benzyloxycarbonyl-Val-Ala-Asp[OMe]fluoromethylketone

\section{Introduction}

Apoptosis is the morphological manifestation of programmed cell death (PCD), a genetically controlled mechanism that is used to remove surplus or damaged cells during embryonic development and in the adult. ${ }^{1}$ The number of known molecules controlling apoptosis has rapidly grown during the past few years. Among them, there is a large family of cysteine proteases that cleave proteins after aspartate residues and are therefore named caspases. These proteases are now considered the core of the apoptotic machinery during the execution phase of apoptosis. ${ }^{2-7}$

Caspases are synthesised as inactive zymogens composed of an amino-terminal prodomain, a large subunit and a small carboxy-terminal subunit. Proteolytic processing of the proenzyme at internal aspartate sites results in the removal of the prodomain and the formation of active heterodimers composed of two large and two small subunits. ${ }^{8-10}$ Active caspases recognise tetrapeptidic target sites, which are cleaved after an aspartate residue and are themselves activated by cleavage at specific aspartate sites. ${ }^{3,4,11}$

Ten different human caspases were initially identified. ${ }^{12,13}$ Since the cloning of two new caspases in mouse (caspase-11 and caspase-12) ${ }^{14}$ and the identification of the human and mouse caspase-14 representatives, ${ }^{15-17}$ the number of mammalian caspases has increased to thirteen. Mammalian caspases are divided functionally into two main groups, one of them directly regulating cell death; the other one involved in the maturation of pro-inflammatory cytokines. ${ }^{4-6,18}$ On the basis of the prodomain structure, caspases are grouped into short-prodomain caspases (caspases -3, -6, -7 and -14) and long prodomain caspases. Long prodomains contain two types 
of motifs involved in protein-protein interactions, the Death Effector Domain (DED) and the Caspase Recruitment Domain (CARD). Apoptotic caspases with long prodomains (caspase-2, -9, -8 and -10) are also known as initiator or apical caspases and are able to be autoactivated when aggregated with adaptor molecules. Caspases with short prodomains (executor or effector caspases) are usually activated by the initiator caspases. ${ }^{19-21}$ Consistent with this, initiator caspases exhibit a substrate preference for cleavage sites found in caspase precursors, while effector caspases act preferentially on other cellular substrates. ${ }^{6}$

Albeit this general outline of the hierarchy of caspases is generally accepted, the particular contribution of an individual caspase to the execution of the cell remains speculative. Analysis of cells from caspase- 3 mutant mice or cell lines deficient in caspase-3 have established that this protein is the main executor caspase. ${ }^{22-25}$ Recently it has also been shown than depletion of either caspase-7 or caspase- 6 from cell free extracts has minimal impact on apoptotic characteristics. ${ }^{26}$ However, while caspase-7 null mice are embryonically lethal, caspase- 6 mutant mice do not exhibit major developmental defects. ${ }^{27}$ Tissue specific regulation and partial redundancy of these proteins may account for these discrepancies.

Caspases homologous have been described in a few taxa. The isolation of $\mathrm{Hv}$ Casp3A and Hv Casp3B in Hydra vulgaris, $^{28}$ and detection of apoptosis tightly linked with morphogenesis in Hydractina echinata metamorphosis ${ }^{29}$ supports the idea that the advent of the apoptosis was instrumental for the evolution of metazoans. Although three novel caspases have been cloned in the nematode Caenorhabditis elegans, ${ }^{30}$ only ced-3 is necessary to promote all the developmental programmed cell death in the worm. ${ }^{31}$

In Drosophila melanogaster, seven different caspases have been described to date. An outline of the apoptotic signalling pathways is currently emerging, where DREDD, DRONC and STRICA may act as initiator caspases, while DCP-1, drICE, DECAY and DAMM are believed to be executor caspases. ${ }^{32,33}$ DREDD and DRONC contain long prodomains carrying DED and CARD motifs respectively $^{34,35}$ and STRICA contains a long prodomain with unique serine/threonine stretches. ${ }^{36}$ DCP-1, drICE, DECAY and DAMM are short-prodomain caspases with a cleavage preference for DXXD sites. ${ }^{37-41}$ It has also been described that DRONC is able to process itself and to activate the effector caspase drICE. ${ }^{42}$ However, the precise pathway of activation of Drosophila caspases have remained elusive, and the evolutionary relations of Drosophila and vertebrate caspases is confusing, most probably due to the higher degree of divergence of the Drosophila genes.

Amphioxus has recently received high attention in the fields of comparative development and genomics. Cephalochordates are the closest extant relatives to vertebrates, and retain a sort of frozen, vertebrate-like, primitive genome. ${ }^{43}$ Increasing molecular data is providing definite evidence for extensive genome duplications during the evolution of vertebrates. Particularly, large increasing in gene numbers, up to full poliploidization, has been claimed at the time of vertebrate origins, just after the split between cephalochordate and vertebrate lineages. ${ }^{4-46}$ Hence, amphioxus is a key landmark for the study of a given vertebrate multigenic family.

Here, we report the first description of programmed cell death in amphioxus early embryos and larvae. Furthermore, we report the isolation, expression and functional characterisation of the first caspase related protein in a non-vertebrate chordate. AmphiCASP-3/7 messenger was detected throughout the embryonic and larval development from the gastrula stage. AmphiCASP-3/7 has a canonical caspase structure that consists of an amino-terminal short prodomain, a large subunit containing a QACRG catalytic consensus site and a carboxy-terminal small subunit. AmphiCASP-3/7 induced cell death when overexpressed in HEK 293T cells, and the removal of the prodomain resulted in an increased ability to promote cell death. Sequence analyses establishes AmphiCASP-3/7 as the vertebrate caspase-3/caspase-7 pre-duplicative and prototypic counterpart. However, both the in vitro enzymatic activity and the inability to rescue the MCF7 caspase-3 deficient cell line most closely relates AmphiCASP-3/7 to caspase-7 than to caspase-3. These results suggest that most properties of the caspase-3 arose after gene duplication at vertebrate origins, thus such properties may be considered novelties during the evolution of vertebrates.

\section{Results}

\section{Evidence for programmed cell death during amphioxus embryonic and larval development}

Programmed cell death has been implicated in a wide range of functions during embryonic development. Thus, selective cell death could be useful in sculpting forms and cavities or deleting structures, adjusting cell numbers or eliminating harmful cells. We have taken advantage of the TdT (terminal desoxynucleotidiyl transferase) mediated dUTP nick endlabelling (TUNEL) technique to detect the characteristic DNA fragmentation which occur during normal developmental cell death. The pattern of apoptosis during amphioxus embryonic and larval development is depicted in Figure 1.

The earliest stage of amphioxus development that showed TUNEL positive nuclei was the neurula. Apoptotic nuclei were never detected at earlier stages. Thus, the first distinct pattern of TUNEL-positive cells was detected in a broad ventral region of the early neurula that corresponds to the two more posterior thirds of the archenteron (Figure $1 \mathrm{~A})$. Later on, as the embryo grew in length, signals were spread over the gastrodermis (Figure 1B). At this stage a strong spotted signal was detected in the anterior left side of the late neurula, in a region where the embryonic mouth will open to the exterior (Figure 1C). At 30-h post fertilisation, a number of the late embryos were found to be almost depleted of apoptotic nuclei. The few remaining embryos exhibited the signal confined to clusters of cells in the embryonic gut (Figure 1D), and at the 2-day larval stage the staining pattern changed substantially (Figure 1E). Apoptotic cells were found in the gill slits, serial 

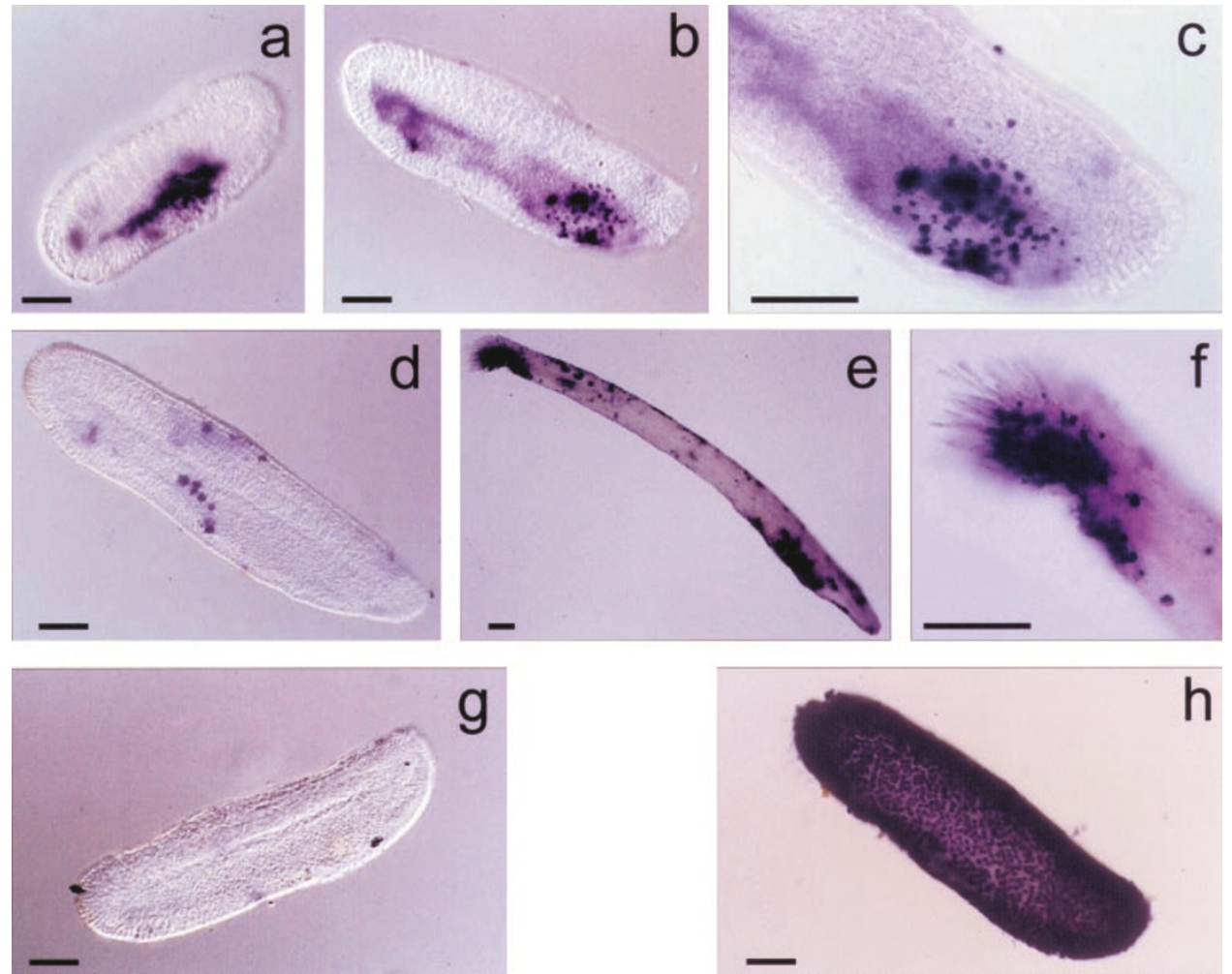

Figure 1 TUNEL whole mount staining of amphioxus embryos shows programmed cell death during development. All embryos are orientated with the anterior part to the right and dorsal part toward the top. (a) Lateral view of a 18-h post-fertilization neurula showing TdT reactivity in the archenteron; (b) 24-h neurula reveals a weak signal in the gastrodermis, and a strong spotted signal in the anterior left side; (c) enlarged vision of b, where the anterior left signal is in focus; (d) Dorsolateral view of a 30-h embryo showing a discrete, spotted signal which corresponds to clusters of nuclei in the gut. (e) 2.5-day larva exhibiting a region of active programmed cell death surrounding the gill slits, and another region in the posterior tip of the organism. Note the scattered signals along the larval body wall. (f) Enlarged image of e showing the posterior zone of the larva, where a number of ciliar structures are located. ( $\mathbf{g}$ and $\mathbf{h})$ Same stage as $\mathbf{b}$, where $\mathbf{g}$ is a negative control in which TdT enzyme was omitted, and $\mathbf{h}$ a positive control performed by pre-treating the embryos with $10 \mu \mathrm{g} / \mathrm{ml}$ of DNAse I for $30 \mathrm{~min}$ at room temperature. Scale bar, $50 \mu \mathrm{m}$

structures which open the pharynx to the exterior. At the same stage, the posterior tip of the organism was strongly stained (Figure 1F).

As a negative control, embryos were included in a TUNEL detection in which TdT enzyme was omitted and as expected, no positive nuclei were found (Figure 1G). As a positive control, embryos were treated with DNase prior to the TUNEL-reaction, which resulted in an extensive staining of nuclei throughout the embryo (Figure $1 \mathrm{H}$ ).

\section{AmphiCASP-3/7, the first caspase described in amphioxus}

To gain insights into the apoptotic mechanisms in amphioxus, we started a search for caspase related sequences in this organism. Degenerate PCR amplification of amphioxus genomic DNA and embryonic cDNA yielded different types of products. Of them, translation of CSPF7 gave an ORF that was $63 \%$ identical with the human caspases-3 and -7 . Screening of a cDNA library using this product as a probe yielded 11 positive clones. Mapping of these clones with seven different restriction enzymes revealed only partially coincident restriction patterns. Sequence analysis showed that all these cDNA clones encode the same protein. On the basis of the homology of the new amphioxus protein with vertebrates caspases-3 and -7 we named it AmphiCASP-3/7. Differences between clones may reflect the normal variability in restriction site polymorphism in wild populations of amphioxus.

The overall structure of the longest messenger exhibited a short 5'UTR (untranslated region) of $169 \mathrm{bp}$ and a long $3^{\prime} U T R$ of around $2 \mathrm{~kb}$ (Figure 2A). Presence of big trailer sequences have been previously reported for human caspase -3 and $-7.47,48$ AmphiCASP-3/7 protein has a predicted sequence of 328 amino acids with a high degree of homology to vertebrate caspases, especially with representatives of the caspase- 3 subfamily. When compared to the GenBank database, it exhibited approximately $55-57 \%$ identity $(71-72 \%$ similarity) with different vertebrate caspase-7 proteins; $49-51 \%$ identity (65-70\% similarity) with vertebrate caspase-3 representatives; $44-$ $48 \%$ identity (57-64\% similarity) with vertebrate caspase-6 proteins; $43-45 \%$ identity $(57-63 \%$ similarity) with Spodoptera frugiperda caspase-1, Drosophila drICE and DCP1 , and was more distantly related to vertebrate caspase-8 (39-41\% identity, 54\% similarity), Drosophila DECAY (38\% identity, $55 \%$ similarity) or Drosophila DAMM $(27 \%$ identity, $42 \%$ similarity). 
A

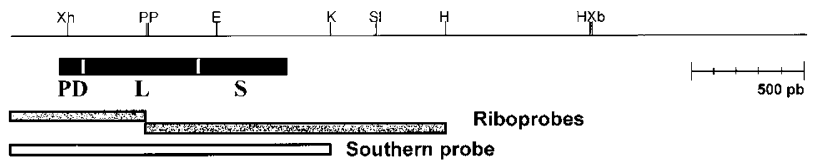

B

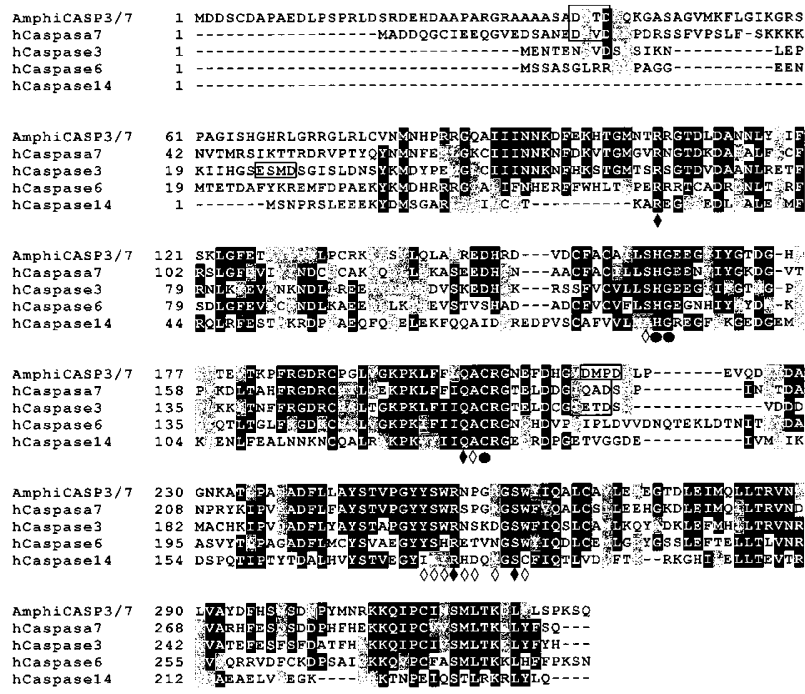

Figure 2 AmphiCASP-3/7 is homologous to the vertebrate effector caspases. (A) Structure of the longest amphioxus AmphiCASP-3/7 messenger. The scale bar indicates size in base pairs. The overall restriction map deduced from different clones is indicated at the top. The predicted structure of the open reading frame is represented below. Regions from which the riboprobes (grey bars) and southern probe (white bar) were designed are also indicated and labelled accordingly. (B) Aminoacid sequence alignment of AmphiCASP-3/7 with human caspases containing short prodomains was obtained using CLUSTAL W program at the European Bioinformatics Institute. Black shaded indicates identity and grey shaded indicates conservation in at least three out of five sequences, respectively. Filled circles indicate residues implicated in catalysis. Open diamonds identify residues which forms the P2$\mathrm{P} 4$ pocket and those implicated in the P1 binding pocket are indicated with filled diamonds. Putative internal cleavage sites are boxed. E, EcoRl; K, Kpnl; H, Hindlll; P, Pstl; S, Sall; Xb, Xbal; Xh, Xhol; PD, Prodomain; L, Large subunit, S, Small subunit

Aminoacidic sequence alignment of AmphiCASP-3/7 with human caspases containing short prodomains showed that the amphioxus caspase exhibited a primary structure clearly related to the so-called effector caspases (Figure 2B). In particular, the putative cleavage sites (open boxes) were well conserved between AmphiCASP-3/7 and human caspases-3 and -7 . These aspartate positions denoted the presence of a short prodomain (PD), a long subunit (L) and a short subunit (S, Figure 2A). The QACRG pentapeptide motif present in most caspases was also conserved in the amphioxus caspase. Moreover, the positions His163, Gly164 and Cys205 of the AmphiCASP-3/7 protein were in agreement with the consensus of residues implicated in catalysis (filled circles). The Arg106, Gln203, Arg255 and Ser261 residues (filled diamonds), which could form a binding pocket for the P1 aspartate acid, were conserved among all proteins in the alignment. However, the putative residues which form the $\mathrm{P} 2-\mathrm{P} 4$ pocket (open diamonds), particularly the Trp254, Asn256, Pro257 and Arg259, ${ }^{10}$ clearly related AmphiCASP-3/7 to human caspase-3 and caspase-7, suggesting a preference of this protease for an aspartate residue at the $\mathrm{P} 4$ position.

\section{Amphioxus caspase $3 / 7$ is expressed throughout development from gastrula to larva}

Whole mount in situ hybridization of amphioxus embryos and larva was performed with specific riboprobes of the AmphiCASP-3/7 messenger (Figure 3). AmphiCASP-3/7 was first expressed by the onset of gastrulation, where a faint signal was seen in mesodermal tissues (Figure 3B). Later during the neurula stage, AmphiCASP-3/7 was detected mainly around the notochord and paraxial mesoderm (Figure $3 C, D)$. Of note is that the body wall epidermis did not express AmphiCASP-3/7 messenger. As embryos grew the signal expanded among almost all tissues except the epidermis and became less intense (Figure 3E,F). At the early larva stage, a strong signal appeared in the posterior ventral region, with an extended shape that may correspond to the neurenteric canal (Figure 3G). This pattern was maintained during larval development. The profile of expression did not correlate with the TUNEL data, except for the onset of expression of AmphiCASP-3/7, which preceded the first apoptotic signals.

\section{AmphiCASP-3/7 could represent the pre-duplicative ancestor of vertebrate caspases-3 and $\mathbf{- 7}$}

Molecular phylogenetic analysis was performed using the whole aminoacidic sequence of all the short prodomain caspases described so far in vertebrates and Drosophila melanogaster. A distance tree constructed by the Neighbour Joining Method is shown in Figure 4. Maximum Parsimony Analysis produced similar results, but with lower bootstrap values. The overall topology of the dendrogram supported three main clades, which corresponded to the caspase-3, caspase- 7 and caspase- 6 vertebrate families, while the human and mouse caspase-14 and the Drosophila caspases were placed apart. AmphiCASP-3/7 sequence located as the sister group of caspase-3 and -7 , with a bootstrap value of $87.4 \%$, and can not be considered closer to either caspase-3 or caspase-7. As Southern blot analysis of genomic DNA from a single organism yielded a hybridization signal that was compatible with the pattern of a single copy gene (Figure 5), we suggest that caspase- 3 and caspase- 7 arose in the lineage leading of vertebrates by duplication of an ancestral gene from which AmphiCASP-3/7 is the amphioxus representative. The tree also predicted that the caspase- 6 family appeared before the split of cephalochordates and vertebrates and could be represented in the amphioxus genome. Whether or not other caspases, in particular caspase-1, caspase-8 or caspase-9 representatives, are present in the amphioxus genome is an unsolved question. The degenerate primers designed to address the cloning of effector caspases in amphioxus do not allow the detection of other caspases. Another strategy would be necessary to characterise the whole amphioxus caspase family. 

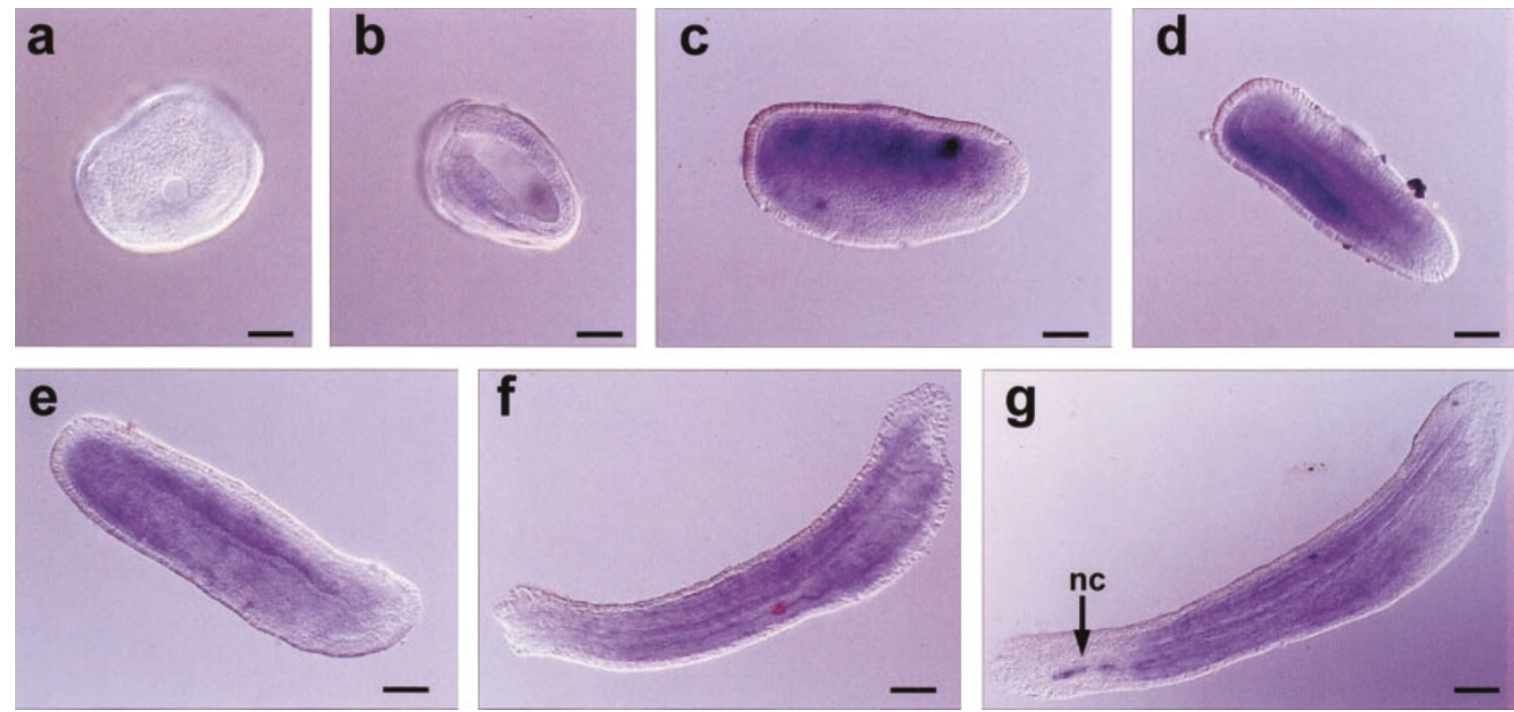

Figure 3 Developmental expression of AmphiCASP-3/7. All embryos are orientated with the anterior part to the right and dorsal part toward the top. Unless otherwise indicated, all embryos are photographed in lateral view. (a) Eight hours early gastrula seen from the blastopore. No signals were still detected at this stage. (b) Side view of a 10-h gastrula. The first detectable signals appeared in the mesodermal layer. (c and d) Side and dorsal view, respectively, of a 12-h middle neurula showing a broad expression of AmphiCASP-3/7, which was stronger in the dorsal region, where the somites, the notochord and the neural tube appeared stained. Note that the epidermal tissues were negative. (e) Dorso-lateral view of an 20-h late neurula in which the notochord is in focus showing expression roughly in all tissues except the epidermis. (f) In the early 30-h larva all the structures except the epidermis were uniformly stained. (g) Later on, in the 36-h larva, the pattern of expression was somewhat more restricted, and a strong signal in the neurenteric canal (nc) appeared. Scale bars, $50 \mu \mathrm{m}$

\section{Overexpression of AmphiCASP-3/7 induces apoptosis in HEK 293T cells}

Several reports on the cloning of new caspases have consistently proved that many caspases induce apoptotic cell death when overexpressed in cultured cells. It is worth nothing that in a few examples the removal of the prodomain was necessary to induce apoptosis. This was the case for drICE overexpression in Drosophila S2 cells ${ }^{38}$ and caspase-7 ectopic expression in either MCF-7 or COS cells. ${ }^{49,50}$ Removal of the prodomain was not necessary for DRONC and DECAY to induce cell death in $3 T 3$ cells $^{35,40}$ or for STRICA to induce death in SL2 cells. ${ }^{36}$ To confirm that AmphiCASP-3/7 is indeed a caspase, we transiently transfected HEK 293T cells with either the full-length AmphiCASP-3/7 or a mutated version lacking the first 41 residues roughly corresponding to the predicted prodomain. Thirty-six hours post-transfection, about $40 \%$ of the cells expressing wild-type AmphiCASP-3/7 exhibited bleebing and chromatin condensation. This represent a threefold increase when compared with cells transfected with the empty pCDNA3 expression vector (Figure 6). Similar results were obtained by expressing human caspase-3 and human caspase-7. Interestingly, removal of the amino-terminal domain of AmphiCASP-3/7 resulted in a considerable increase in the percentage of apoptotic cells. Altogether, these results clearly demonstrate that AmphiCASP-3/7 is a typical caspase that induces programmed cell death when overexpressed in mammalian cells. Moreover, differences between the cell death inducing activity of whole AmphiCASP-3/7 or the truncated form lacking the prodomain, strongly suggest a role for the amino-terminal domain of
AmphiCASP-3/7 in regulating the activity of this enzyme, thus demonstrating that it is not only structurally, but also functionally, a prodomain.

\section{Amphioxus caspase- $3 / 7$ protein has a substrate specificity similar to the executor caspases}

To further characterise the substrate preference of the amphioxus caspase, we expressed the wild-type AmphiCASP-3/7 and the catalytic mutated form in which Cysteine 205 was changed to Serine (C205S) in E. coli. A caspase assay was performed with the soluble fraction of bacterial lysates using fluorogenic peptidic substrates as described previously. ${ }^{40}$ Recombinant AmphiCASP-3/7 protein efficiently cleaved the caspase-3/caspase-7 substrate Ac-DEVD-afc, while the caspase- 6 substrate Ac-VEID-afc and the caspase8 substrate Ac-IETD-afc were not processed (Figure 7A). As expected, the mutation of the Cys 205 to Ser (C205S) completely abolished the AmphiCASP-3/7 activity. Preincubation of the lysates with the specific executor caspase inhibitor z-DEVD-fmk and the broad range inhibitor z-VADfmk also prevented processing of Ac-DEVD-afc peptides.

AmphiCASP-3/7 substrate preference was quite similar to that found for human caspase-7. On the contrary, in our hands human caspase-3 showed significant cleavage activity not only on the Ac-DEVD-afc peptides, but also on the Ac-VEID-afc and the Ac-IETD-afc peptides. Even at saturating protein concentrations neither AmphiCASP-3/7 nor caspase-7 significantly cleaved the Ac-VEID-afc substrate, while caspase- 3 was able to process equally both Ac-DEVD-afc and Ac-VEID-afc substrates (Figure 7B). It has recently been demonstrated that caspase- 3 exhibits 


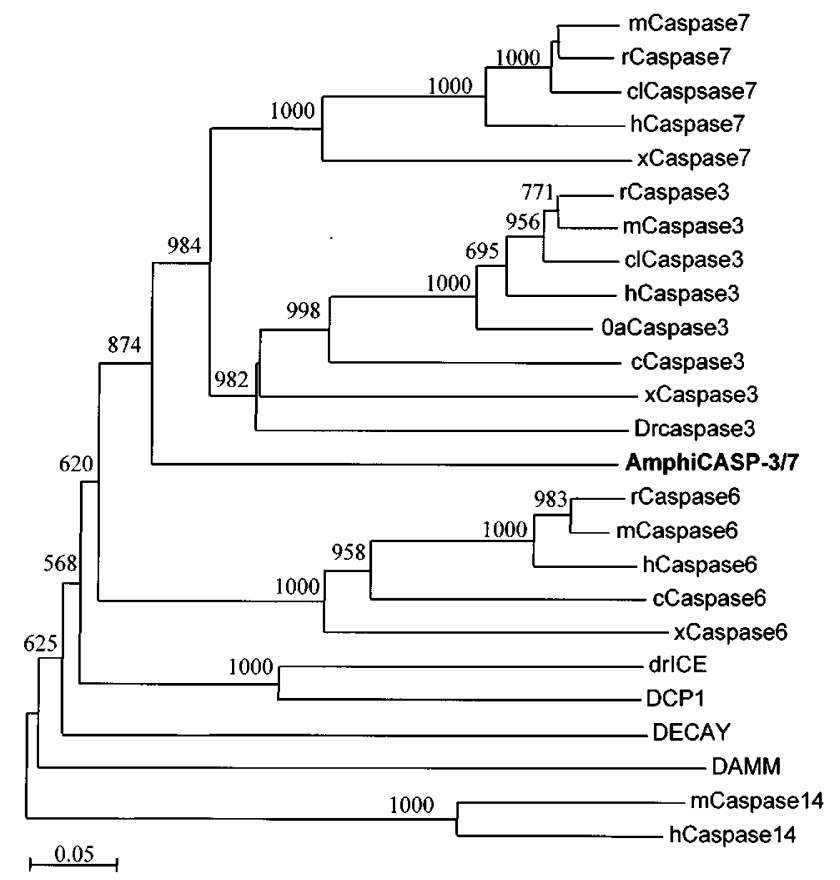

Figure 4 Phylogenetic relationships among different caspases. Distance tree constructed by the Neighbour Joining Method from a protein alignment of vertebrates effector caspase $-3,-7$ and -6 , human and mouse caspase-14, Drosophila melanogaster DCP1, DECAY, drICE and DAMM, and the amphioxus sequence reported here. Numbers at the branch nodes indicate bootstrap values on 1000 replicates. Bottom bar indicates the branch length corresponding to 0.05 substitutions per site. Gene species nomenclature is used as follows: c, chick; cl, hamster; Dr, zebra-fish; h, human; m, mouse; $\mathrm{Oa}$, sheep; $r$, rat; $x$, Xenopus

150 -fold greater activity than caspase- 7 when a valine is placed at P4 position. ${ }^{51}$ The absence of activity on AcVEID-afc and Ac-IETD-afc substrates agrees with the higher sequence homology of AmphiCASP-3/7 with caspase-7 than with caspase-3.

\section{AmphiCASP-3/7 protein can not rescue the phenotype of MCF7 caspase-3 deficient cells}

Since it is becoming clearer that each type of cell expresses a complex subset of caspases, we took advantage of the fact that the MCF7 breast carcinoma cell-line lacks active caspase $-3^{22}$ to further characterise AmphiCASP-3/7 during cellular apoptosis. MCF-7 cells fail to degrade several substrates upon apoptosis induction. From this, it was concluded that caspase- 3 is required for $\alpha$-fodrin processing, ${ }^{23}$ and also for proper cleavage and activation of both DFF45 and gelsolin. ${ }^{52}$ MCF-7 cells were transiently transfected with carboxy-terminal FLAG tagged forms of caspase-3, AmphiCASP-3/7 or a truncated form of AmphiCASP-3/7 lacking the prodomain, then their ability to process either $\alpha$-fodrin or DFF45 upon staurosporine treatment was assessed by Western blot. As expected, overexpression of caspase-3 in MCF7 restored the ability of these cells to produce the $120-\mathrm{kDa}$ fragment resulting from the specific cleavage of $\alpha$-fodrin by active caspase-3. Moreover, the $p-11$ carboxy-terminal fragment of DFF45, which results from the

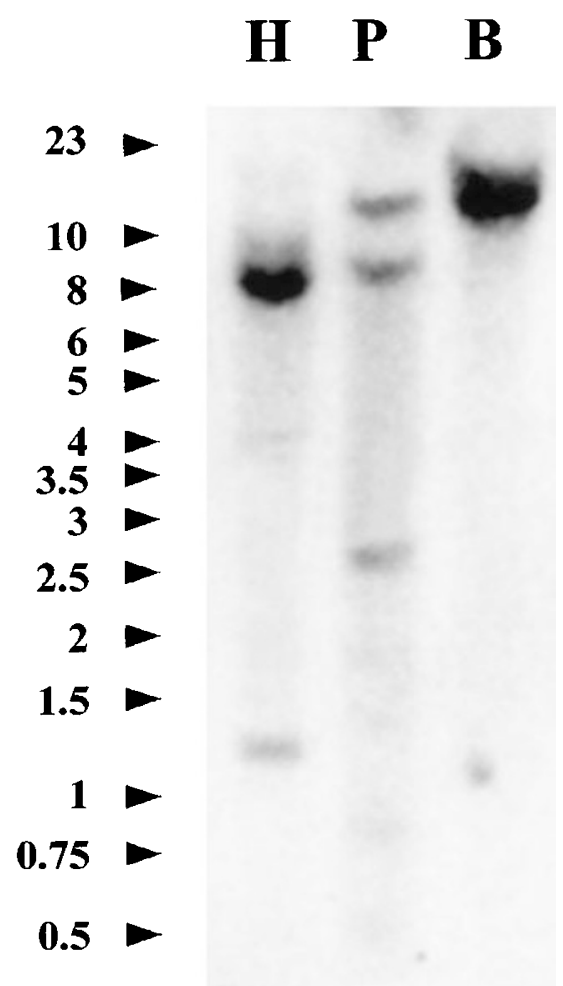

Figure 5 Southern blot analysis suggests that AmphiCSP-3/7 is a single copy gene. Thirty micrograms of DNA from a single organism were digested with the corresponding restriction enzyme: $\mathrm{H}$, Hindll, P, Pstl, B, BamHI. Probing the membrane with an $1.3 \mathrm{~kb} 5^{\prime}$ fragment of the amphioxus cDNA yielded a hybridisation pattern which was compatible with the presence of no other genes related to AmphiCASP-3/7. Detection of several bands in the Pstl lane may indicate the presence of internal sites for this restriction enzyme. Numbers on the left indicates size of the DNA markers in kilobases

cleavage and activation of DFF45 by caspase-3, was also observed in MCF7 cells expressing caspase- 3 when they were treated with staurosporine (Figure 8A). On the contrary, neither $\alpha$-fodrin nor DFF45 were properly processed in MCF7 cells expressing AmphiCASP-3/7 or its truncated version. It is well known that internucleosomal DNA fragmentation depends on the activity of CAD, which is activated when its inhibitor ICAD is processed by active caspase-3. Consistently with this, MCF7 cells do not exhibit DNA laddering when treated with different apoptotic stimulus. Transient transfection of caspase-3 was able to rescue the nuclear phenotype in MCF7 cells and a pattern of DNA degradation was observed (Figure 8B). However, ectopic expression of either wild-type AmphiCASP-3/7 or the truncated form lacking the prodomain did not promote any change in the apoptotic DNA degradation of MCF7 cells. Thus, $\alpha$-fodrin cleavage, DFF45 cleavage and activation, and DNA degradation were not observed in staurosporine-induced apoptotic cells transfected with either AmphiCASP-3/7 or truncated AmphiCASP-3/7, albeit the level of expression of these proteins was comparable to that of caspase-3 (as detected by Western blot using an anti-FLAG antibody). Altogether, these results strongly support the hypothesis that AmphiCASP-3/7 is more closely related to caspase- 7 than to caspase-3. 


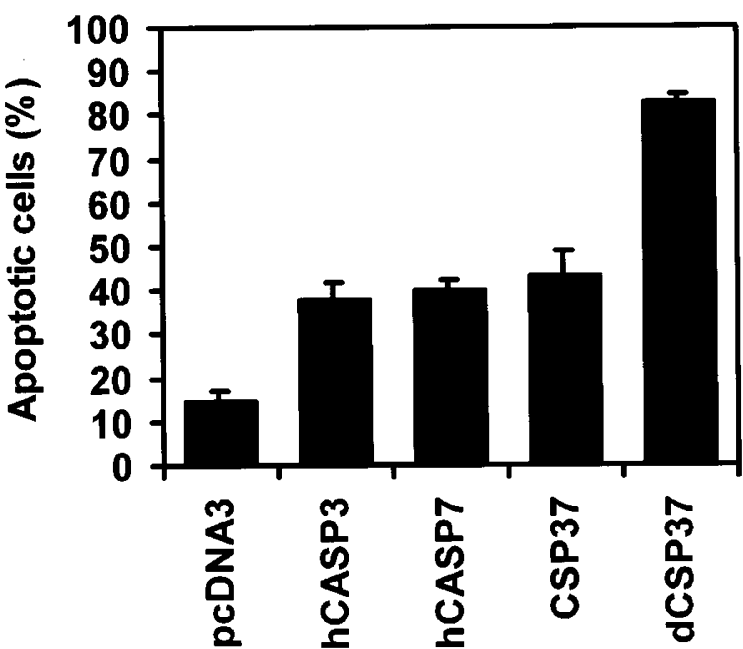

Figure 6 AmphiCASP-3/7 promotes cell death when over expressed in human cells. HEK 293T cells were co-transfected with $6 \mu \mathrm{g}$ of the indicated expression plasmids and $1.5 \mu \mathrm{g}$ of a pEGFP-expressing reporter construct. The data (mean \pm S.E.M., $n=3$ ) represent the percentage of apoptotic nuclei, as visualised by the Hoechst nuclear staining, in the population of EGFP positive cells. The experiment was repeated once with similar results. AmphiCASP-3/7 (CSP37) promoted cell death to a similar level when compared to human caspase-3 (hCASP3) and caspase-7 (hCASP7). Deletion of the prodomain increased twofold the death inducing ability of AmphiCASP$3 / 7$ (dCSP37). Transfection with the empty vector was including as a contro (pcDNA3)

\section{Discussion}

Animal development is based on multiple cellular functions, and recently programmed cell death has been receiving much attention. The contribution of programmed cell death to the development of vertebrates and a few invertebrate taxa, which include Arthropods, Nematodes and Cnidarians, has been well documented. Here, we describe for the first time the pattern of developmental cell death in amphioxus, the closest invertebrate relative to vertebrates. ${ }^{43}$ Amphioxus offers a stereotypical model of development which gives rise to a primitive embryonic body form representative of the vertebrate embryo.

The pattern of DNA fragmentation detected by the TUNEL technique clearly demonstrated that apoptosis takes place during amphioxus development. There were several examples of normal programmed cell death, which occurred in a reproducible manner at specific stages of amphioxus development. Since treatment in vivo of amphioxus embryos with caspase inhibitors involves complex logistics, we were unable to perform these experiments. Therefore, we can only speculate that this pattern of cell death could be related with morphogenesis during amphioxus development. Thus, the restricted signal detected in the ventral part of the neurula may be an example of cavitation related with the archenteron formation. Later on, at the late neurula stage, the gastrodermic signal could reflect the renewal of the epithelia. Interestingly, the clusters of cells that were detected at this stage in the left anterior body wall could correspond to the position of mouth formation. In amphioxus, the mouth opening is an asymmetric process that involves an endodermal thickening in the left wall of the archenteron.

In the larva, the gill slit region appeared strongly stained. Gill slits develop from the endoderm, then migrate to fuse with the ectoderm and break through the body wall. Their formation could represent a good example of programmed cell death involved in hollowing out solid structures. The tail also exhibited active programmed cell death in the larva stage. Consistently with this, cells located in the most posterior tip of the larva exhibit prominent cilia that will be lost in the adult, presumably by apoptosis.

It is worth noting the great variability in the distribution of TUNEL staining for each stage analyzed in all the experiments carried out. Thus, a fraction of the embryos were negative for each stage analyzed. It has been proposed that programmed cell death takes place during development in a well controlled temporal window, and cells that undergo cell death are degraded rapidly. As amphioxus embryos coming from a fertilized spawn are not perfectly synchronous, the rapid clearance of dead cells may explain the existence of embryos showing no staining.

Apart from the well stereotyped and reproducible patterns of cell death described above, there were some positive signals which change from embryo to embryo, with no defined pattern and an almost random distribution. These signals could be explained by the elimination of damaged cells, where patches of positive cells may originate from a single cell. These scattered signals were often localised along the body wall. As amphioxus embryo and larva show ectodermal derived cilia, which are retained until metamorphosis begins, the epidermic positive cells mentioned above may be a sign of the selective deletion of the ciliar epithelium.

AmphiCASP-3/7 was ubiquitously expressed throughout amphioxus development in most tissues, which suggest a role of AmphiCASP-3/7 in conferring the ability to die rather than instructing the apoptotic cell death during development. An exception was the high accumulation of AmphiCASP-3/7 messenger detected in the neurenteric canal, structure which connects temporarily the neural tube with the gut cavity that is eliminated during the larval development. How this up-regulation of AmphiCASP-3/7 expression could be related to the deletion of the neurenteric canal is an unsolved question. Nevertheless, in our hands TUNEL whole mount experiments have never revealed any indication of apoptosis inside this canal.

Mammalian effector caspases are a subgroup of apoptotic caspases mainly characterised by the presence of a short prodomain, an initiator caspase dependent activation, and a preference of cleavage sites found in cellular substrates. Among them, caspase-3 and caspase-7 seem to share a common origin by gene duplication. They exhibit $56 \%$ identity ( $72 \%$ similarity) at the aminoacid sequence level, and they share five intronic positions in their coding region. Mapping of caspase- 3 in $4 q 34$ and of caspase-7 in $10 \mathrm{q} 25,{ }^{53}$ two chromosomal regions which exhibit traits of paralogy, strongly support that both genes arose in vertebrates by genome duplication. Moreover, the in vitro activities of caspase- 3 and caspase- 7 are nearly indistinguishable. 

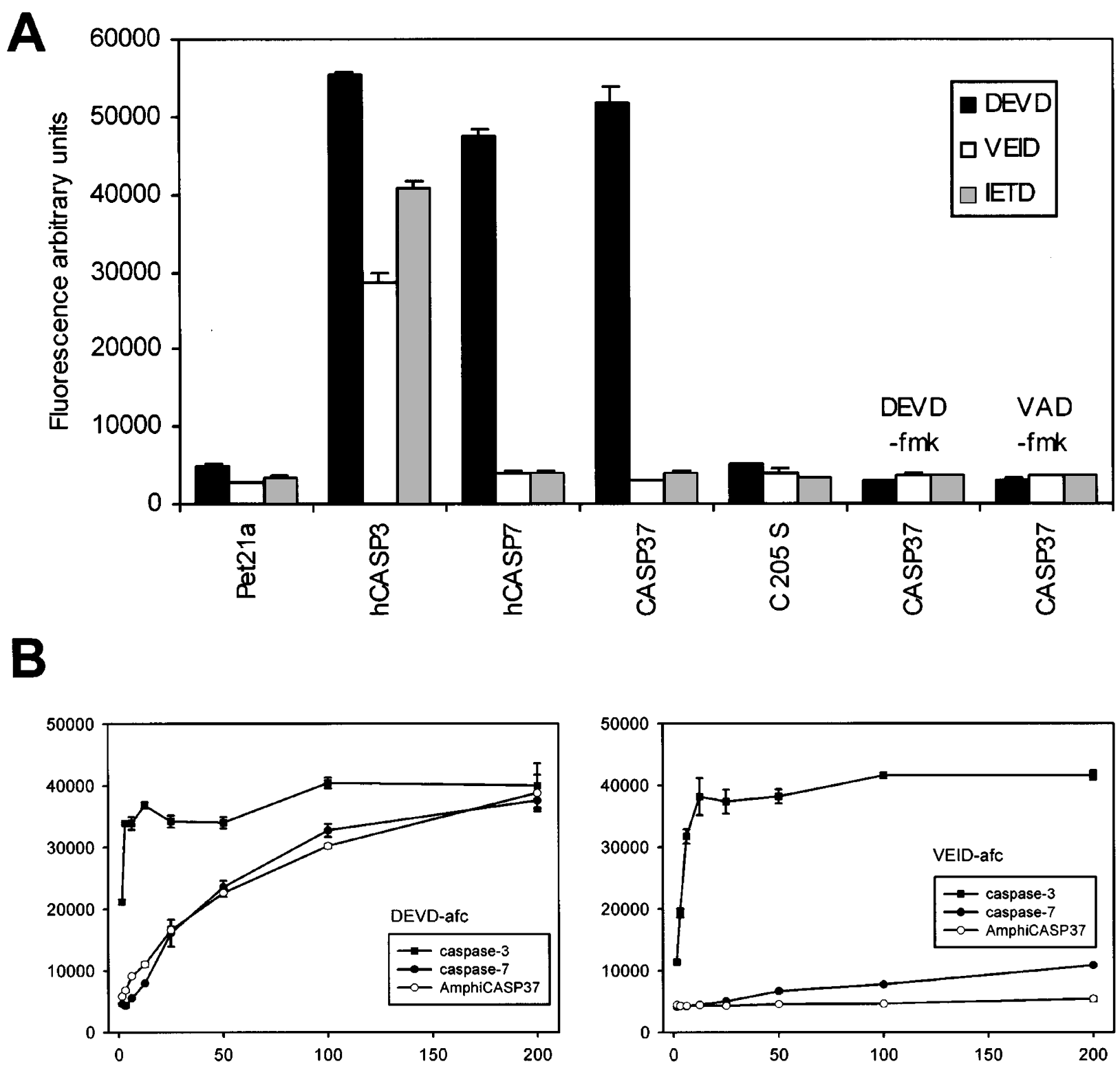

Figure 7 AmphiCASP-3/7 has a substrate specificity similar to caspase-7. (A) Fifty micrograms of bacterial lysates from clones expressing recombinant human caspase-3 (hCASP3), human caspase-7 (hCASP7), amphioxus AmphiCASP-3/7 (CASP37) and mutated AmphiCASP-3/7 (C205S) were assessed for the ability of cleave different fluorogenic substrates for $7 \mathrm{~h}$ at $37^{\circ} \mathrm{C}$. AmphiCASP-3/7 extracts were also either left untreated or pre-incubated with $20 \mu \mathrm{M}$ of the inhibitors DEVDfmk and VAD-fmk. As a control, extracts from cultures transformed with the empty vector were included (Pet21a). Caspase activity was monitored measuring the -afc release on Ac-DEVD-afc (black bars) Ac-VEID-afc (white bars) and Ac-IETD-afc (grey bars) substrates as arbitrary fluorescence units in a Bio-Tek FL 600 fluorimeter (Izasa, Spain) at $360 \mathrm{~nm}(40 \mathrm{~nm}$ bandwidth) of excitation and $530 \mathrm{~nm}(25 \mathrm{~nm}$ bandwidth) of emission. Data ( \pm S.E.M.) were derived from one experiment performed in triplicate. (B) Different concentrations $(\mu \mathrm{g})$ of bacterial lysates expressing recombinant human caspase-3 (filled squares), caspase-7 (filled circles) and AmphiCASP-3/7 (open circles) were assessed for their ability to process Ac-DEVD-afc (left plot) and Ac-VEID-afc (right plot) as described in (A)

The caspase coding sequence described in amphioxus was compatible with a hypothetical ancestral caspase-3/ caspase-7 protein. First, structural homology, analyzed by phylogenetic methods, stated AmphiCASP-3/7 is equally (and closely) related to vertebrate's caspase -3 and -7 . Second, albeit the degenerate PCR approach has allowed amplifying other amphioxus sequences related to caspases (JR Bayascas and $\mathrm{J}$ Comella, unpublished results), no other homologous to caspase- 3 nor to caspase- 7 has been cloned. Third, moderate stringency screening of cDNA libraries yielded a high number of positive clones, all coding for the same protein. Fourth, Southern blot analysis does not suggest the existence of genes closely related to AmphiCASP-3/7.

Evolution of vertebrates involved an increase in anatomical complexity, which was supported by genome wide duplications followed by maintenance of multiple members of many gene families. ${ }^{44-46}$ Altogether our data suggest that vertebrate caspases- 3 and -7 arose by duplication of a gene closely related to AmphiCASP-3/7 in the vertebrates lineage. 

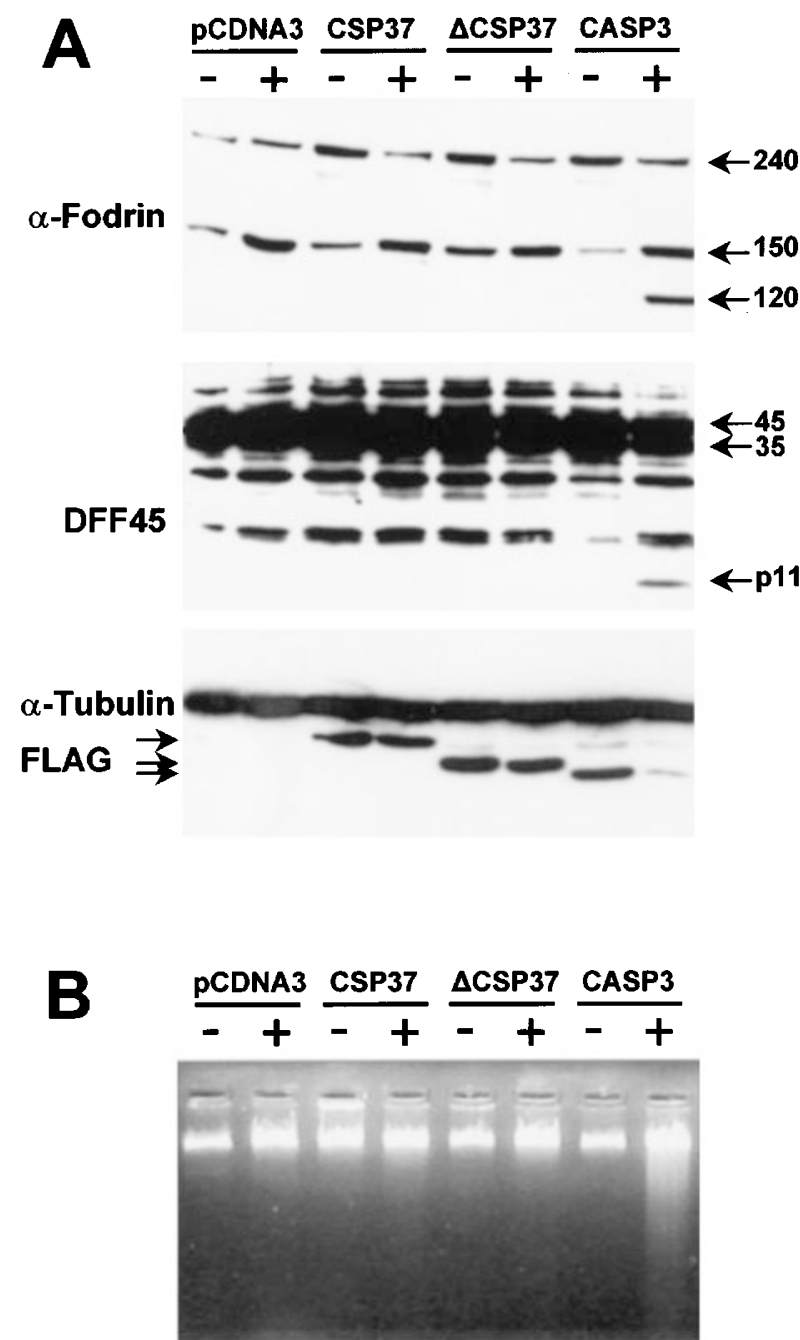

Figure 8 AmphiCASP-3/7 does not restore the apoptotic phenotype in staurosporine-treated MCF-7 cells. MCF7 cells transiently transfected with the indicated plasmids (empty vector, pCDNA3; AmphiCASP-3/7, CSP37; truncated AmphiCASP-3/7, $\triangle$ CASP37; human caspase-3, CASP3) were treated with $500 \mathrm{nM}$ staurosporine $(+)$ or left untreated $(-)$. (A) RIPA extracts were loaded either into $6 \%$ or $15 \%$ polyacrilamide gels for the $\alpha$-fodrin and DFF45 Western blot analysis, respectively. The molecular weights that are indicated in the right part of the figure are those reported for the intact proteins and the corresponding specific fragmentation products. Membranes were stripped and reprobed with a FLAG antibody to assess the expression of the transfected constructs, and further reprobed with a $\alpha$-tubulin antibody to control protein loading. Only caspase- 3 expressing cells were able to degrade $\alpha$-fodrin and DFF45 in their corresponding p120 and p11 specific fragments. (B) Analysis of the DNA degradation of the same transfections used above. A clear pattern of DNA degradation was only observed in the lane corresponding to staurosporine-treated cells expressing caspase-3

Nevertheless, overall sequence homology indicated great similarity of AmphiCASP-3/7 with caspase-7 representatives. Although the second putative cleavage site of AmphiCASP-3/7 was equally related to both caspase-3 and caspase-7, the caspase target site located between the prodomain and the large subunit was well conserved between amphioxus caspase and caspase-7. Moreover, AmphiCASP-3/7 shares with caspase-7 an almost exclusive preference for DEVD peptides in the flourogenic caspase assay, while caspase- 3 is able to process also Ac-VEID-afc and Ac-IETD-afc substrates. The lack of complementation of MCF7 cells transfected with AmphiCASP-3/7 ruled out the possibility of AmphiCASP-3/7 being a caspase-3 orthologue.

It is well known that caspase-3 is the main effector caspase in vertebrates, accounting for cleavage of many cellular substrates which are degraded during apoptosis. Since our results suggest that AmphiCASP-3/7 is a bona fide representative of the ancestral caspase-3/caspase-7 duplication, it could be proposed that caspase- 3 has acquired most of its functional innovations during the evolution of vertebrates, while caspase-7 has retained a more ancestral condition.

\section{Materials and Methods}

\section{Species}

Adults Amphioxus (Branchiostoma floridae) were collected from Old Tampa Bay (Florida, USA). Ripe male and females were induced to spawn by electro-shocking. After in vitro fertilization, embryos were allowed to develop to the desired stage at $23^{\circ} \mathrm{C}^{54}$

\section{Whole mount detection of apoptosis on amphioxus embryos using TUNEL methodology}

Detection of apoptotic DNA degradation was carried out with the ONCOR ApopTag in situ Apoptosis Detection kit (INTERGEN, USA) following supplier instructions, with some modifications. Embryos stored in $70 \%$ ethanol were rehydrated in PBT $(0.1 \%$ Tween in PBS), washed in PBS (phosphate buffered saline), digested with $2.5 \mu \mathrm{g} / \mathrm{ml}$ proteinase $\mathrm{K}$ for $5 \mathrm{~min}$ at $37^{\circ} \mathrm{C}$, washed in PBS, and equilibrated in ONCOR Equilibration Buffer. Terminal deoxynucleotidyl transferase reaction was carried out according to the manufacturer instructions using digoxigenin-dUTP as substrate, for $12 \mathrm{~h}$ at $4^{\circ} \mathrm{C}$ plus $2 \mathrm{~h}$ at $37^{\circ} \mathrm{C}$. The reaction was terminated by rinsing the embryos in PBS$1 \mathrm{mM}$ EDTA for $40 \mathrm{~min}$ at $37^{\circ} \mathrm{C}$, followed by washes in TBST $(0.14 \mathrm{M}$ sodium chloride, $10 \mathrm{mM}$ potassium chloride, $25 \mathrm{mM}$ Tris- $\mathrm{Cl} \mathrm{pH} 7.0$ and $0,1 \%$ Tween) and a heat inactivation step of $20 \mathrm{~min}$ at $65^{\circ} \mathrm{C}$. Subsequent inmunodetection and chromogenic reaction was essentially adapted from the whole mount hybridization protocol described below. Briefly, the embryos were incubated with $0.5 \%$ Blocking Reagent (Boehringer Mannheim), $2 \mathrm{mg} / \mathrm{ml}$ BSA in PBT for $1 \mathrm{~h}$ at room temperature, followed by incubation with anti-Digoxigenin antibody coupled to alkaline phosphatase (Boehringer Mannheim) diluted 1:3000 in the same blocking buffer, overnight at $4^{\circ} \mathrm{C}$. Embryos were extensively washed for $24 \mathrm{~h}$ in PBS and staining developed using nitro blue tetrazolium (NBT) and 5-bromo-4-chloro3-indolyl phosphate (BCIP) substrates. Reaction was stopped within 60 min with PBS. Colour reaction was fixed with $4 \%$ paraformaldehyde in PBS and stained embryos were mounted in glycerol for photography.

\section{Whole mount in situ hybridization}

Detection of AmphiCASP-3/7 messenger during development was carried out essentially as described. ${ }^{55}$ Ribonucleotide probes were synthesised from the Pstl/Hindlll $1.4 \mathrm{~kb}$ fragment or from the most $5^{\prime}$ Pstl $0.7 \mathrm{~kb}$ subclone (see Figure 2A). Both probes gave rise to identical results. 


\section{Cloning and sequencing of AmphiCASP-3/7 cDNA}

PCR (Polymerase chain reaction) amplification was performed from either genomic DNA or CDNA libraries. Primers fully degenerated corresponding to the peptides LSHGEE, specific of vertebrates effector caspases, and $(\mathrm{I} / \mathrm{V}) \mathrm{QAC}(\mathrm{Q} / \mathrm{R}) \mathrm{G}$, which contains the active site and is present in most caspases, were designed. The primers sequences were CSP-1: CTGTC(ATCG)CA(AT)GG(ATCG)GA(AG)GA and CSP-4: CC(ATCG)(TC)(GT)(AG)CA(ATCG)GC(TC)TG(ATC$G) A$, for the forward and reverse primers, respectively. PCR conditions were $94^{\circ} \mathrm{C} / 20 \mathrm{~s}, 45-50^{\circ} \mathrm{C} / 20 \mathrm{~s}$ and $72^{\circ} \mathrm{C} / 30 \mathrm{~s}$ for 35 cycles. Products of around 150 base pair (bp) in length were blunt ended, cloned in pBluescript SK (Stratagene, La Jolla, California) and sequenced with the Abi PRISM BigDie terminator Cycle Sequencing Kit (PE Applied Biosystems).

An amphioxus cDNA library representative of 6 -h to 20 -h post fertilization embryos (a gift from $\mathrm{J}$ Langeland) was screened under middle stringency conditions using the CSPF7 degenerate PCR product as a probe. Approximately $10^{6}$ p.f.u. were hybridised in the buffer described by Church and Gilbert ${ }^{56}$ at $60^{\circ} \mathrm{C}$. Positive clones were plaque purified and excised in pBluescript II (SK+) according to manufacturer's instructions. Since sequencing of positive clones with degenerate primers was proved unsuccessful, degenerate PCR was performed to confirm the resulting cDNAs, which were then mapped by restriction analysis and sequenced with specific primers.

\section{Genomic analysis by Southern blot}

Genomic DNA was extracted from a single organism, digested with three different restriction enzymes, resolved on $0.7 \%$ agarose gels and transferred onto Hybond-N Amersham membranes. ${ }^{57}$ Hybridisation conditions were the same as for library screening. Briefly, hybridisation was carried out in $0.5 \mathrm{M} \mathrm{Na}_{2} \mathrm{HPO}_{4} \mathrm{pH} 7.2,1 \mathrm{mM}$ EDTA (sodium ethylenediaminetetraacetic acid) $\mathrm{pH} 8.0,1 \% \mathrm{BSA}$ (Bovine serum albumin, V Fraction, Sigma), $7 \%$ SDS (sodium dodecyl sulphate) and $100 \mathrm{ng}$ of a $10^{9}$ c.p.m./ $\mu \mathrm{g}$ specific ${ }^{32} \mathrm{P}$ random primed labelled probe corresponding to the $K p n l$ band of 1.4 kilobases $(\mathrm{kb})$, for $20 \mathrm{~h}$ at $60^{\circ} \mathrm{C}$. Filters were washed in $40 \mathrm{mM} \mathrm{Na}_{2} \mathrm{HPO}_{4}$ buffer $\mathrm{pH} 7.2,1 \mathrm{mM}$ EDTA, $5 \%$ SDS for $15 \mathrm{~min}$ at $60^{\circ} \mathrm{C}$ two times, then with phosphate buffer $40 \mathrm{mM} \mathrm{pH} \mathrm{7.2,} 1 \mathrm{mM}$ EDTA and $1 \%$ SDS $15 \mathrm{~min}$ at $60^{\circ} \mathrm{C}$ twice. Exposition was performed on super $\mathrm{RX}$ from Fuji with intensification screens for 1 week.

\section{Phylogenetic analysis}

Alignment of vertebrate and Drosophila caspases with short prodomains with that of amphioxus was performed by using the CLUSTAL-X computer program. ${ }^{58}$ Phylogenies were reconstructed both by the Neighbour Joining Method ${ }^{59}$ of the CLUSTAL-X package and the Maximum Parsimony Method of the MEGA program version 2.0. ${ }^{60}$ Confidence of the results thus generated was assessed by performing either 1000 or 100 bootstrap re-samplings of the data for the distance and parsimony methods, respectively.

\section{Cell lines, expression constructs and transfections}

Human breast carcinoma MCF7 cells ${ }^{61}$ were cultured in DMEM containing $10 \%$ foetal calf serum. Human embryonic kidney $293 \mathrm{~T}$ cells ${ }^{62}$ were cultured in MEM containing $10 \%$ horse serum. Unless otherwise stated, all media and reagents were purchased from Sigma (St. Louis, MO, USA).

The 984 bp coding region of AmphiCASP-3/7 was amplified from a cDNA clone by polymerase chain reaction with primers CSP37NHF:
CCCAAGCTTCATATGGACGATTCGTGCGACGCTCCA and CSP37HR: CCCCAAGCTTCTGTGATTTCGGAGACAGGAA (nucleotides corresponding to CDNA sequence are underlined). Amplified product was purified and cloned in the Ndel/Hindll sites of PET21a (Novagen, Darmstadt, Germany).

The whole coding sequence of AmphiCASP-3/7 and a form lacking the prodomain were amplified with forward primers CSP37EF: GGAATTCATGGACGATTCGTGCGACGC and $\triangle$ CSP37EF: GGAATTCATGGCAACGAAGGGCGCATCGGCA respectively, and the reverse primer CSP37XR: CCCGTCTAGACTGTGATTTCGGAGACAGGA (nucleotides corresponding to cDNA sequence are underlined, and the new start codon of the truncated caspase is indicated in italic). Both products were cloned in the EcoRI/Xbal sites of a pCDNA3-derived vector that fused the FLAG epitope at the carboxy-terminus of the protein.

Human caspase- 3 and -7 were PCR amplified and cloned following similar strategies, with primers designed to amplify the ORF derived from the GenBank sequences with accession numbers NM 004346: and NM 001227, respectively.

The catalytic cysteine residue of AmphiCASP-3/7 was mutated to a serine residue by the Quickchange mutagenesis strategy (Stratagene, La Jolla, California) with the rTth DNA polymerase XL (Perkin Elmer) by using the PET21a constructs as templates. A second silent mutation, which generates a new restriction site, was introduced to make easier the selection of positive constructs. For the AmphiCASP3/7 directed mutagenesis, primers used were CSP37-C/S-F: CCCAAACTCTTCTTTCTACAaGCtTCTCGAGGGAATGAGTTTGACC and CSP37-C/S-R: GGTCAAACTCATTCCCTCGAgAaGCtTGTAGAAAGAAGAGTTTGGG, which introduced a new Hindlll restriction site (underlined). Changed positions are indicated in lower case.

For the MCF-7 complementation experiments, approximately $10^{6}$ cells per condition were seeded in 60-mm dishes. Twenty-four hours later cells were transfected with $15 \mu$ of the Lipofectamine 2000TM reagent (Life Technologies Inc, Rockville, USA) plus $10 \mu \mathrm{g}$ of the desired DNA following manufacturer's instructions. Thirty-six hours post-transfection cells were treated with $500 \mathrm{nM}$ of staurosporine for $6 \mathrm{~h}$ or left untreated.

For the HEK 293T induced cell death, a total of $10^{5}$ cells were seeded in $35-\mathrm{mm}$ dishes. Twenty-four hours later, cells were cotransfected in triplicate with $6 \mu \mathrm{g}$ of the adequate expression plasmids by the calcium phosphate method. ${ }^{57} 1.5 \mu \mathrm{g}$ of enhanced green fluorescent protein (EGFP) expressing plasmid was included systematically in all experiments to recognise transfected cells during counting. The total amount of transfected plasmid was adjusted with empty-pcDNA3 to be always the same in individual experiments. Thirty-six hours post-transfection cells were stained with $0.5 \mu \mathrm{g} / \mathrm{ml}$ of Hoechst 33258, and the number of apoptotic versus normal nuclei in EGFP expressing cells was scored using and inverted Olympus microscope equipped with epifluorescence optics under UV illumination. Experiments were repeated twice and no less than 100 cells were counted per condition. Statistical significance was determined by Student's $t$-test.

\section{Western blot analysis}

Cells were extracted in RIPA total buffer $(10 \mathrm{mM}$ Tris- $\mathrm{HCl}, \mathrm{pH} 7.4$, $1 \mathrm{mM}$ EDTA, $150 \mathrm{mM} \mathrm{NaCl}, 1 \%$ Nonidet P-40, 1\% deoxycholate, $0.1 \%$ SDS, $1 \mathrm{mM}$ PMSF) and protein was quantitated in the supernatants (Bio Rad DC Protein Assay, Bio Rad, Hercules, CA, USA). Fifty $\mu \mathrm{g}$ of protein per condition were loaded in SDS-polyacrylamide gels. Proteins were electrotransferred from the gels to Immobilon filters (Millipore, Bedford, MA, USA) with a semidry methodology and they 
were reacted with the appropriate primary antibody. Immunoblots were further incubated with the adequate secondary antibodies conjugated with peroxidase (Sigma). Subsequently, blots were developed with the chemiluminescent SuperSignal West Dura Extended Duration Substrate (Pierce, Rockford, IL, USA). The $\alpha$-fodrin (Chemichon), DFF45 (StressGen), $\alpha$-tubulin (Sigma) and FLAG (Sigma) antibodies were purchased commercially.

\section{DNA ladder analysis}

MCF7 cells were homogenised in $600 \mu$ of NDS lysis buffer $(0.5 \mathrm{M}$ EDTA, $1 \%$ lauryl sarcosine, $10 \mathrm{mM}$ Tris- $\mathrm{HCl} \mathrm{pH}$ 9.5). Homogenates were clarified by centrifuging at $13.000 \times g$ for $15 \mathrm{~min}$, supernatants were collected to a new tube and extracted with phenol:chloroform:isoamyl alcohol $(25: 24: 1)$. DNA was precipitated with two volumes of cold ethanol and 0.5 volumes of $7.5 \mathrm{M}$ ammonium acetate. Precipitate was washed once in $70 \%$ ethanol and resuspended in TE $(1 \mathrm{mM}$ EDTA, $10 \mathrm{mM}$ Tris- $\mathrm{HCl}$, pH 8.0) containing DNase-free RNase at a final concentration of $20 \mu \mathrm{g} / \mathrm{ml}$. DNA was analyzed in $1.8 \%$ agarose gels in TAE buffer (1 mM EDTA, $40 \mathrm{mM}$ Tris-acetate $\mathrm{pH}$ 7.6).

\section{Recombinant proteins and caspase assays}

Recombinant caspases were produced by transformation of Escherichia coli BL21 cells with the PET21a constructs. Overnight cultures were diluted $1: 20$ and growth $3 \mathrm{~h}$ at $37^{\circ} \mathrm{C}$. Fresh cultures were induced with $1 \mathrm{mM}$ IPTG (isopropyl-1-thio- $\beta$-D-galactopyranoside) for $5 \mathrm{~h}$ at room temperature. Cells were pelleted and lysed by sonication in caspase assay buffer (0.1 M HEPES pH 7.0, 10\% PEG (polyethylene glycol), 0.1\% 3-(3-cholamidopropyl)dimethylammonio)1-propanesulphonic acid (CHAPS) and $10 \mathrm{mM}$ DTT (dithiotheitol). Fifty $\mu \mathrm{g}$ of total protein from cleared lysates were either left untreated or treated for $15 \mathrm{~min}$ at $37^{\circ} \mathrm{C}$ with $20 \mu \mathrm{M}$ of the caspase inhibitors zDEVD-fmk (benzyloxycarbonyl-Asp[OMe]-Glu[OMe]-Val-Asp[OMe]fluoromethylketone) and z-VAD-fmk (benzyloxycarbonyl-Val-Ala-As$\mathrm{p}[\mathrm{OMe}]-$ fluoromethylketone). Samples were then incubated with $50 \mu \mathrm{M}$ of the fluorogenic peptide substrates (Enzyme Systems Products, Livermore, CA, USA) Ac-DEVD-afc (acetyl-Asp[OMe]Glu[OMe]-Val-Asp[OMe]-7-amino-4-trifluoromethylcoumarin), AcVEID-afc (acetyl-Val-Glu[OMe]-Ile-Asp[OMe]-7-amino-4-trifluoromethylcoumarin) or Ac-IETD-afc (acetyl-Ile-Glu[OMe]-Thr-Asp[OMe]7-amino-4-trifluoromethylcoumarin) and assayed for caspase activity as described. ${ }^{63}$

\section{Acknowledgements}

We thank the people from the Molecular Neurobiology Group at Lleida and the Amphioxus Team at Barcelona for their contribution to the elaboration of this work. In particular we acknowledge Xavi Dolcet, Joaquim Egea, Mario Encinas and Carolina Minguillón. We specially thank to Anna Santamaria for her help in searching for amphioxus caspases and to Jane Thompson for checking the English. We thank A Manonelles (Hospital Universitari Arnau de Vilanova, Lleida, Spain) for help with the ABI PRISM 310 Automatic Sequence Analyzer (Perkin Elmer) and Isabel Sanchez, Inma Montoliu and Roser Pané for technical support. We also thank Nick Holland and Linda Holland for their help with the amphioxus embryos collection. This study was supported by grants from Proyectos FEDER (1FD97-0514-002-01) and Plan Nacional Salud y Farmacia (SAF 2000-0164-002-01) from Spanish Government, RTD project number QLG3-CT-1999-00602 from the European Union and Telemarató de TV3. JR Bayascas is a postdoctoral researcher supported by FEDER (1FD97-0514-002-01), VJ Yuste and E Benito hold postgraduate fellowships from Telemarató de TV3.

\section{Accession number}

AmphiCASP-3/7 sequence has been deposited in the GenBank database under Accession number AF412335

\section{References}

1. Jacobson MD, Weil M and Raff MC (1997) Programmed cell death in animal development. Cell 88: 347-354

2. Cohen GM (1997) Caspases: the executioners of apoptosis. Biochem J. 326:1 16

3. Salvesen GS and Dixit VM (1997) Caspases: intracellular signaling by proteolysis. Cell 91: $443-446$

4. Thornberry NA and Lazebnik Y (1998) Caspases: enemies within. Science 281: $1312-1316$

5. Earnshaw WC Martins LM and Kaufmann SH (1999) Mammalian caspases: structure, activation, substrates, and functions during apoptosis. Annu Rev Biochem. 68: 383-424

6. Nicholson DW (1999) Caspase structure, proteolytic substrates, and function during apoptotic cell death. Cell Death Differ. 6: 1028-1042

7. Wolf BB and Green DR (1999) Suicidal tendencies: apoptotic cell death by caspase family proteinases. J. Biol. Chem. 274: 20049-20052

8. Walker NP, Talanian RV, Brady KD, Dang LC, Bump NJ, Ferenz CR, Franklin S, Ghayur T, Hackett MC, Hammill LD, Herzog L, Hugunin M, Houy W, Mankovich JA, McGuiness L, Orlewicz Z, Paskind M, Pratt CA, Reis P, Summani A, Terranova M, Weich JP, Xiong L, Moller A, Tracey DE, Kamen R and Wong WW (1994) Crystal structure of the cysteine protease interleukin-1 beta-converting enzyme: a (p20/p10)2 homodimer. Cell 78: 343-352

9. Wilson KP, Black JA, Thomson JA, Kim EE, Griffith JP, Navia MA, Murcko MA, Chambers SP, Aldape RA, Raybuck SA and Livingston DJ (1994) Structure and mechanism of interleukin-1 beta converting enzyme. Nature 370: 270-275

10. Rotonda J, Nicholson DW, Fazil KM, Gallant M, Gareau Y, Labelle M, Peterson EP, Rasper DM, Ruel R, Vaillancourt JP, Thornberry NA and Becker JW (1996) The three-dimensional structure of apopain/CPP32, a key mediator of apoptosis. Nat. Struct. Biol. 3: 619-625

11. Cryns V and Yuan J (1998) Proteases to die for. Genes Dev. 12: 1551 - 1570.

12. Alnemri ES, Livingston DJ, Nicholson DW, Salvesen G, Thornberry NA, Wong WW and Yuan J (1996) Human ICE/CED-3 protease nomenclature. Cell 87: 171

13. Thornberry NA (1999) Caspases: a decade of death research. Cell Death Differ. 6: $1023-1027$

14. Van de Craen M, Vandenabeele $P$, Declercq W, Van den Brande I, Van Loo G, Molemans F, Schotte P, Van Criekinge W, Beyaert R and Fiers W. (1997) Characterization of seven murine caspase family members. FEBS Lett. 403: $61-69$

15. Van de Craen M, Van Loo G, Pype S, Van Criekinge W, Van den brande I, Molemans F, Fiers W, Declercq W and Vandenabeele P (1998) Identification of a new caspase homologue: caspase-14. Cell Death Differ. 10: 838-846

16. Hu S, Snipas SJ, Vincenz C, Salvesen G and Dixit VM (1998) Caspase-14 is a novel developmentally regulated protease. J. Biol. Chem. 273: 29648-29653

17. Ahmad M, Srinivasula SM, Hegde R, Mukattash R, Fernandes-Alnemri T and Alnemri ES (1998) Identification and characterization of murine caspase-14, a new member of the caspase family. Cancer Res. 58: 5201-5205

18. Slee EA, Adrain C and Martin SJ (1999) Serial killers: ordering caspase activation events in apoptosis. Cell Death Differ. 6: 1067-1074

19. Green DR and Reed JC (1998) Mitochondria and apoptosis. Science 281: $1309-1312$

20. Kumar S (1999) Mechanisms mediating caspase activation in cell death. Cell Death Differ. 6: 1060-1066

21. Salvesen GS and Dixit VM (1999) Caspase activation: the induced-proximity model. Proc. Natl. Acad. Sci. USA 96: 10964-10967

22. Janicke RU, Sprengart ML, Wati MR and Porter AG (1998)Caspase-3 is required for DNA fragmentation and morphological changes associated with apoptosis. J. Biol. Chem. 273: 9357-9360 
23. Janicke RU, Ng P, Sprengart ML and Porter AG (1998) Caspase-3 is required for alpha-fodrin cleavage but dispensable for cleavage of other death substrates in apoptosis. J. Biol. Chem. 273: 15540-15545

24. Woo M, Hakem R, Soengas MS, Duncan GS, Shahinian A, Kagi D, Hakem A, McCurrach M, Khoo W, Kaufman SA, Senaldi G, Howard T, Lowe SW and Mak TW (1998) Essential contribution of caspase 3/CPP32 to apoptosis and its associated nuclear changes. Genes Dev. 12: 806-819

25. Zheng TS, Schlosser SF, Dao T, Hingorani R, Crispe IN, Boyer JL and Flavell RA (1998) Caspase-3 controls both cytoplasmic and nuclear events associated with Fas-mediated apoptosis in vivo. Proc. Natl. Acad. Sci. USA 95: 13618-13623

26. Slee EA, Adrain C and Martin SJ (2001) Executioner caspase-3, -6, and -7 perform distinct, non-redundant roles during the demolition phase of apoptosis. J. Biol. Chem. 276: 7320-7326

27. Zheng TS and Flavell RA (2000) Divinations and surprises: genetic analysis of caspase function in mice. Exp. Cell Res. 256: 67-73

28. Cikala M, Wilm B, Hobmayer E, Bottger A and David CN (1999) Identification of caspases and apoptosis in the simple metazoan Hydra. Curr. Biol. 9: 959-962

29. Seipp S, Schmich J and Leitz T (2001) Apoptosis - a death-inducing mechanism tightly linked with morphogenesis in Hydractina echinata (Cnidaria, Hydrozoa). Development 128: 4891-4898

30. Shaham S (1998) Identification of multiple Caenorhabditis elegans caspases and their potential roles in proteolytic cascades. J. Biol. Chem. 273: 3510935117

31. Metzstein MM, Stanfield GM and Horvitz HR (1998) Genetics of programmed cell death in C. elegans: past, present and future. Trends Genet. 14: 410-416

32. Kumar S and Doumanis J (2000) The fly caspases. Cell Death Differ. 11: 1039 1044

33. Adrain $C$ and Martin SJ (2001) Search for Drosophila caspases bears fruit: STRICA enters the fray. Cell Death Differ. 8: 319-323

34. Chen P, Rodriguez A, Erskine R, Thach T and Abrams JM (1998) Dredd, a novel effector of the apoptosis activators reaper, grim, and hid in Drosophila. Dev. Biol. 201: $202-216$

35. Dorstyn L, Colussi PA, Quinn LM, Richardson H and Kumar S (1999) DRONC, an ecdysone-inducible Drosophila caspase. Proc. Natl. Acad. Sci. USA 96: 4307 4312

36. Doumanis J, Quinn L, Richardson H and Kumar S (2001) STRICA, a novel Drosophila melanogaster caspase with an unusual serine/threonine-rich prodomain, interacts with DIAP1 and DIAP2. Cell Death Differ. 8: 387-394

37. Song Z, McCall K and Steller H (1997) DCP-1, a Drosophila cell death protease essential for development. Science 275: 536-540

38. Fraser AG and Evan GI (1997) Identification of a Drosophila melanogaster ICE/ CED-3-related protease, drICE. EMBO J. 16: 2805-2813

39. Fraser AG, McCarthy NJ and Evan GI (1997) drICE is an essential caspase required for apoptotic activity in Drosophila cells. EMBO J. 16: 6192-6199

40. Dorstyn L, Read SH, Quinn LM, Richardson H and Kumar S (1999) DECAY, a novel Drosophila caspase related to mammalian caspase-3 and caspase-7. J. Biol Chem. 274: 30778-30783

41. Harvey NL, Daish T, Mills K, Dorstyn L, Quinn LM, Read SH, Richardson H and Kumar S (2001) Characterization of the Drosophila caspase, DAMM. J. Biol. Chem. 276: 25342-25350

42. Hawkins CJ, Yoo SJ, Peterson EP, Wang SL, Vernooy SY and Hay BA (2000) The Drosophila caspase DRONC cleaves following glutamate or aspartate and is regulated by DIAP1, HID, and GRIM. J. Biol. Chem. 275: 27084-27093

43. Minguillón C, Ferrier D, Cebrián $C$ and Garcia-Fernàndez J (2002) Gene duplications in the prototypical cephalochordate amphioxus. Gene 287: 121 128

44. Garcia-Fernandez J and Holland PW (1994) Archetypal organization of the amphioxus Hox gene cluster. Nature 370: 563-566
45. Holland PW, Garcia-Fernandez J, Williams NA and Sidow A (1994) Gene duplications and the origins of vertebrate development. Development Suppl. $125-133$

46. Holland PW and Garcia-Fernandez J (1996) Hox genes and chordate evolution. Dev. Biol. 173: 382-395

47. Fernandes-Alnemri T, Litwack G and Alnemri ES (1994) CPP32, a novel human apoptotic protein with homology to Caenorhabditis elegans cell death protein Ced-3 and mammalian interleukin-1 beta-converting enzyme. J. Biol. Chem. 269: $30761-30764$

48. Fernandes-Alnemri T, Takahashi A, Armstrong R, Krebs J, Fritz L, Tomaselli KJ, Wang L, Yu Z, Croce CM, Salveson G, Earnshaw WC, Litwack G and Alnemri ES (1995) Mch3, a novel human apoptotic cysteine protease highly related to CPP32. Cancer Res. 55: 6045-6052

49. Lippke JA, Gu Y, Sarnecki C, Caron PR and Su MS (1996) Identification and Characterization of CPP32/Mch2 Homolog 1, a Novel CysteineProtease Similar to CPP32. J. Biol. Chem. 271: $1825-1828$

50. Duan H, Chinnaiyan AM, Hudson PL, Wing JP, He W-Wand Dixit VM (1996) ICELAP3, a Novel Mammalian Homologue of the Caenorhabditis elegans Cell DeathProtein Ced-3 Is Activated during Fas- and Tumor Necrosis Factorinduced Apoptosis. J. Biol. Chem. 271: 1621-1625

51. Stennicke HR, Renatus M, Meldal M and Salvesen GS (2000) Internally quenched fluorescent peptide substrates disclose the subsite preferences of human caspases 1, 3, 6, 7 and 8. Biochem. J. 350: 563-568

52. Tang D and Kidd VJ (1998) Cleavage of DFF-45/ICAD by multiple caspases is essential for its function during apoptosis. J. Biol. Chem. 273: 28549-28552

53. Tiso N, Pallavicini A, Muraro T, Zimbello R, Apolloni E, Valle G, Lanfranchi G and DanieliGA (1996) Chromosomal localization of the human genes, CPP32, Mch2, Mch3, and Ich-1, involved in cellular apoptosis. Biochem. Biophys. Res. Commun. 225: 983-989

54. Holland LZ and Holland ND (1993) Embryos and larva of invertebrate deuterostomes. In "Essential Developmental Biology: A Practical Approach" Stern CD and Holland PWH, eds. Oxford: IRL Press, pp 21-32

55. Holland PW, Holland LZ, Williams NA and Holland ND (1992) An amphioxus homeobox gene: sequence conservation, spatial expression during development and insights into vertebrate evolution. Development 116: 653-661

56. Church GM and Gilbert W (1984) Genomic sequencing. Proc. Natl. Acad. Sci. USA 81: 1991-1995

57. Sambrook J, Fritsch EF and Maniatis T (1989) Molecular Cloning: A Laboratory Manual, 2nd edn, Cold Spring Harbor Laboratory, Cold Spring Harbor, NY

58. Thompson JD, Gibson TJ, Plewniak F, Jeanmougin F and Higgins DG (1997) The CLUSTAL_X windows interface: flexible strategies for multiple sequence alignment aided by quality analysis tools. Nucleic Acids Res. 25: 4876-4882

59. Saitou $N$ and Nei M (1987) The neighbor-joining method: a new method for reconstructing phylogenetic trees. Mol. Biol. Evol. 4: 406-425

60. Kumar S, Tamura K, Jakobsen IB and Nei M (2001) MEGA2: Molecular Evolutionary Genetics Analysis software. Bioinformatics 17: 1244-1245

61. Soule HD, Vazguez J, Long A, Albert S and Brennan M. (1973) A human cell line from a pleural effusion derived from a breast carcinoma. J. Natl. Cancer Inst. 5: $1409-1416$

62. Graham FL, SmileyJ, Russell WC and Nairn R(1977) Characteristics of a human cell line transformed by DNA from human adenovirus type 5. J. Gen. Virol. 36: $59-74$

63. Yuste VJ, Bayascas JR, Llecha N, Sanchez-Lopez I, Boix J and Comella JX (2001) The absence of oligonucleosomal DNA fragmentation during apoptosis of IMR-5 neuroblastoma cells: disappearance of the caspase-activated DNase. J. Biol. Chem. 276: 22323-22331 